\title{
*ABA effects in kinship allomorphy \& syncretism
}

\author{
Tran Truong*
}

\begin{abstract}
Morphological contiguity domains are pockets of natural language grammar wherein formal irregularity in one component predicts co-irregularity in a related, and often more marked, component. At the surface level, they foreclose certain allomorphic and/or distributional possibilities, producing so-called *ABA effects. Contiguity phenomena have been documented in the study of comparatives, case, pronouns, tense/aspect, inter multa alia. To this expanding list, this study adds kinship. It shall be shown that nonsingular pronouns in Lower Arrernte exemplify an apparent *ABA allomorphy-constraining distribution in which the agnate-disharmonic and non-agnate forms must co-supplete. An implementation using toy features demonstrates that the emergence of at least some *ABA patterns may be artifactual of how a paradigm is set up, and that Lower Arrernte nonsingulars do not instantiate Bobaljik (2012)'s containment hypothesis. These results are consonant with a picture of contiguity effects as a group of etiologically and derivationally heterogeneous phenomena, instead of an unambiguous diagnostic for syntactic hierarchical structure.
\end{abstract}

Keywords. morphology; contiguity; Arandic; kinship; allomorphy; syncretism

1. Introduction. This study understands contiguity to refer to the organization of grammatical subsystems of wherein discontinuous patterns of formal identity are either extremely rare or outright impossible. The contiguity effect par excellence remains comparative suppletion, as described by Bobaljik (2012), which can be summarized in a bipartite generalization:

\section{(1) The Comparative-Superlative Generalization}

a. Part 1: If the comparative degree of an adjective is suppletive, then the superlative is also suppletive (i.e., with respect to the positive).

b. Part 2: If the superlative degree of an adjective is suppletive, then the comparative is also suppletive (i.e., with respect to the positive).

Generalization (1) is instantiated by paradigms like tall-taller-tallest (an AAA distribution, in which all grades share a root), bad-worse-worst (an ABB distribution, in which the nonpositive grades share a root), and Old Irish maith-ferr-dech ('good-better-best', an ABC distribution, in which no grades share a root). Crucially, across a sample of greater than 300 typologically, areally, and genealogically diverse languages, Bobaljik observes no unambiguous cases of paradigms like *good-better-goodest (a *ABA distribution, in which the noncomparative grades share a root). This absence is argued to result from a containment effect, in which the formal representation of the superlative properly contains that of the comparative. Containment should be understood as a contiguity phenomenon in which the 'final' category is the most formally or representationally complex:

(2) Transparent containment in Persian (adapted from Bobaljik 2012:4,31)

*The author thanks Karlos Arregi, Itamar Francez, Amy Dahlstrom, Andrew Nevins, Bernard Comrie, Jerrold Sadock, Farrell Ackerman, and especially Sasha Wilmoth for their insights on earlier versions of this work. Author: Tran Truong, University of Chicago (elixir@uchicago.edu). 

a. [ $\left.\operatorname{kam}_{\mathrm{ADJ}}\right]$ 'few'
b. [[ kam $\left.\mathrm{ADJ}] \operatorname{tar}_{\mathrm{CMPR}}\right]$ 'fewer'
c. [[[ kam $\left.\left.\operatorname{ADJ}_{\mathrm{A}}\right] \operatorname{tar}_{\mathrm{CMPR}}\right]$ in $\left._{\mathrm{SPRL}}\right]$ 'fewest (lit. fewerest)'
d. *[[ ADJ ] SPRL ]

In (2c), the superlative is composed of the comparative and additional superlativizing material. Assuming that these structures are also active in languages in which containment is not overt, $\mathrm{ABB}$ and $\mathrm{ABC}$ patterns can be generated via the combination of $(2 \mathrm{a}-\mathrm{c})$ and Pāninian ordering (Anderson 1992), in which a more specific allomorph (e.g., the suppletive comparative root worse) outcompetes a less specific one (i.e., the regular positive root bad) at postsyntactic insertion. Concomitantly, the absence of $*$ ABA patterns follows from the illicitness of structure (2d): a superlative structure that excludes the comparative would permit *bad-worse-baddest.

1.1. HETEROGENEITY IN CONTIGUITY. Significantly, Bobaljik's analysis provides a proof of principle for the use of surface *ABA distributions in order to diagnose the presence and character of syntactic hierarchical structure. Containment phenomena have since been argued to be active in the organization of case (Caha 2008), pronouns (Smith et al. 2018), nominalizations (Jabłońska \& Marinov 2011), clusivity (Moskal 2018), tense/aspect (Adamson 2019), inter multa alia. Two conundra loom large across this expanding body of work.

\section{(3) Two puzzles concerning *ABA distributions}

a. Methodological: How should subcategories in a proposed contiguity domain be ordered?

b. Theoretical: Need every surface *ABA distribution correspond to a containment structure, or indeed, any kind of structure?

Caha (2017)'s study of Blansitt's generalization stands out as particularly instructive with respect to both puzzles. Within the dative-allative-locative functional subsequence, absolute syncretism is observed only across contiguous categories, and the 'middle' category is the most formally or representionally complex:

\begin{tabular}{|c|c|c|c|}
\hline & DAT & ALL & LOC \\
\hline ABC: Basque & -ri & -ra & -an \\
\hline AAA: Japanese & $-\underline{\mathrm{ni}}$ & $-\underline{n i}$ & $-\underline{n i}$ \\
\hline AAB: Pite Saami & $-\bar{j}$ & $-\bar{j}$ & $-\bar{n}$ \\
\hline ABB: Dime & - in $^{-}$ & -ó & -ó \\
\hline$* \mathrm{ABA}$ & in & to & in \\
\hline Tigrinya & ne & nab & $\underline{\mathrm{ab}}$ \\
\hline Proposed structure & [DAT] & [DAT, LOC] & [LOC] \\
\hline
\end{tabular}

Table 1. Blansitt's generalization.

In Table 1, DAT refers to the recipient in a ditransitive construction (e.g., I gave it to Kyle, ALL refers to a goal of motion (e.g., I went to the park), and LOC refers to the place where (e.g., I am in Japan). These data contrast with comparative suppletion on multiple dimensions. First, whereas Bobaljik discusses (im)possible patterns of allomorphy, Caha discusses (im)possible patterns of absolute syncretism. That is, -ni should not be understood as three homophonous markers of different cases, but rather as a single case marker whose trifunctionality results from a systematic dynamic of licit conflation. The *ABA pattern describes a version 
of English in which *I gave in Kyle is grammatical, a result of an illicit conflation of the noncontiguous dative and locative meanings.

Second, whereas Persian kam-tar-in (few-CMPR-SPRL) suggests that the superlative is the most marked category, Tigrinya $n$ - $a b$ (DAT-LOC) suggests that the allative is the most marked. If some *ABA distributions only emerge in markedness-increasing sequences (e.g., positive < comparative $<$ superlative), whereas others only emerge in markedness-alternating sequences (e.g., dative $<$ allative $>$ locative), then morphological contiguity phenomena may not form an etiologically or analytically homogeneous natural class. As well, the organization of data into paradigms onto which putative contiguity domains are projected becomes a non-trivial, theoryladen task.

2. Contiguity in kinship. This study identifies kinship to be a domain rich in surface *ABA distributions. Specifically, it will be shown that moiety-sensitive nonsingular pronouns in Arrernte (Arandic, Pama-Nyungan, 4,500 speakers across all varieties according to the 2016 Australian census), as characterized by descriptive grammars, are subject to an apparent allomorphyconstraining contiguity effect. The use of toy features points to an analysis in which apparent AAB allomorphy should be reanalyzed as AAB, or more drastically, dismissed as a *ABA environment completely. Secondly, it will be shown that Héritier's First Fundamental Law of Kinship (Hage 1997) can be restated as a syncretism-constraining contiguity effect, blocking certain co-lexicalizations of kinship terms.

2.1. BACKGROUnD. Arrernte (also Aranda) describes a cluster of varieties spoken in the Northern Territory, Australia. This study focuses on the Lower Arrernte variety (also Alenjerntarrpe, dormant as of 2011), in which nonsingular pronouns are sensitive to generation (harmonic vs. disharmonic) and moiety (agnate vs. non-agnate). A shameful level of didactic and expository simplification follows; for a discussion that does more justice to the complexity and logic of the system, consult McConvell et al. (2018).

(4) Principle of Generational Cyclicity (Hale 1966)

a. Male EGO is harmonic with respect to members of his own generation and members of all even-numbered generations counting away from his own.

b. Male EGO is disharmonic with respect to members of all odd-numbered generations counting away from his own.

By Principle (4), a man is harmonic to his grandparents and grandchildren. He is disharmonic to his children and parents.

Moiety (also skin or section) refers to the division of the society into groups, for the purposes of determining marriageability. The system is organized around two patrimoities, A and $\mathrm{B}$, and two matrimoieties, $\mathrm{C}$ and $\mathrm{D}$. If $\mathrm{A} / \mathrm{B}$ status is paternally inherited, and C/D status is maternally inherited, then each person belongs to one of four moieties: $\mathrm{AC}, \mathrm{AD}, \mathrm{BC}$, and BD. Marriages are only possible between fully contrastive moieties: AC members marry BD members, and AD members marry BC members. ${ }^{1}$

Moietal combinatorics

a. $\mathrm{AC}$ father $+\mathrm{BD}$ mother produce $\mathrm{AD}$ children.

\footnotetext{
${ }^{1}$ Individual Arrernte languages use different terms for these moieties; an abstract notation has been selected here for maximum generalizability.
} 
b. $\mathrm{AD}$ father $+\mathrm{BC}$ mother produce $\mathrm{AC}$ children.

c. $\mathrm{BD}$ father $+\mathrm{AC}$ mother produce $\mathrm{BC}$ children.

d. $\mathrm{BC}$ father $+\mathrm{AD}$ mother produce $\mathrm{BD}$ children.

(6) Principle of Agnatic Kinship (Yallop 1977, 1982)

a. $\mathrm{AC}$ is agnate with respect to $\mathrm{AD}$ (i.e., sharing a patrilineal descent line).

b. $\mathrm{AC}$ is non-agnate with respect to $\{\mathrm{BC}, \mathrm{BD}\}$ (i.e., cognate [sharing a matrilineal descent line] to $\mathrm{BC}$ and marriageable to $\mathrm{BD}$ ).

c. AC is non-agnate with respect to all outgroup members (e.g., Westerners).

2.2 Singular PRONOUNS. Arrernte pronouns contrast five cases (ergative, nominative, accusative, dative, genitive), three numbers (singular, dual, plural), but not clusivity or gender. Strictly speaking, the forms below are from Western Arrernte, but Arandic singulars are fairly uniform across all varieties (Yallop 1982:98). As singulars, they do not take into account principles $(4,6)$.

(7) Western Arrernte singular pronouns
a. atha ' $1 \mathrm{SG}$; I'
b. unta ' $2 \mathrm{SG}$; thou'
c. irra ' $3 \mathrm{sG}$; she/he'

3. Generation- and moiety-sensitive nonsingular pronouns. Arrernte nonsingulars come in three sets, which both Hale (1966) and Yallop (1977) call set I, set II, and set III. Set I is used when all referents are agnate and harmonic (e.g., a group containing a man and his brothers). Set II is used when all referents are agnate, but at least one is disharmonic (e.g., a group containing a father and his children). Set III is used when at least one referent is non-agnate (e.g., a group containing a man and his grandmothers); it is additionally generation-insensitive.

Data below are from Hale (1966), and have been retransliterated to follow the orthography proposed in Yallop (1982). Yallop (1977:99) reports slightly different forms for this variety, which could either signify interspeaker variation or mistranscription on the part of either party. In either case, the allomorphic generalization remains the same: if the agnate-disharmonic formant is suppletive, then the non-agnate formant is also suppletive.

\begin{tabular}{lcccc} 
& $\begin{array}{c}\text { AGNATE-HARMONIC } \\
\text { (e.g., 'my brother \& I') }\end{array}$ & $\begin{array}{c}\text { AGNATE-DISHARMONIC } \\
\text { (e.g., 'my father \& I') }\end{array}$ & $\begin{array}{c}\text { NON-AGNATE } \\
\text { (e.g., 'my mother \& I') }\end{array}$ \\
\hline 1DU & ili-rn & il-ak & il-anth & AAA \\
2DU & ang-athir & mpil-ak & mpil-anth & ABB \\
3DU & il-athir & al-ak & al-anth & ABB \\
1PL & un-ar & un-ak-ir & un-anth-ir & AAA \\
2PL & ang-arrii & ar-ak-ir & ar-anth-ir & ABB \\
3PL & il-arrii & inn-ak-ir & inn-anth-ir & ABB \\
\hline
\end{tabular}

Table 2. *ABA in Lower Arrernte nonsingular pronouns.

4. Featural decomposition. Returning to the methodological puzzle presented in (3), there is no principled reason to organize Table 2 in the order of agnate-harmonic $>$ agnate-disharmonic $>$ non-agnate, other than to harmonize with Hale and Yallop's descriptive practice. This section argues that the use of toy features, even those that stretch the bounds of both emic and 
etic plausibility (cf. Wierzbicka 2013), may still be useful in the determination of relative markedness within a proposed contiguity domain.

For a start, the analysis proposes four binary features to account for the person and number contrasts.

(8) Person \& number features (Harbour 2011, 2016)

a. first: [+author, +participant]

b. second: [-author, + participant $]$

c. third: [-author, - participant $]$

d. singular: [+singular, - augmented]

e. dual: $[-$ singular, -augmented $]$

f. plural: $[-$ singular, +augmented]

Second, suppose that male EGO has a generational specification of $[\mathbb{G}: 0]$. From EGO's perspective, his father would be $[\mathbb{G}: 1]$, and his son would be $[\mathbb{G}:-1]$. Counting one more generation away, his grandfather would be $[\mathbb{G}: 2]$, his grandson would be $[\mathbb{G}:-2]$, and so on. Modular arithmetic can be used to group harmonic generations together:

(9) Harmony features

a. harmonic: $[\mathbb{G} \equiv 0 \quad(\bmod 2)]$

b. disharmonic: $[\mathbb{G} \equiv 1 \quad(\bmod 2)]$

(possible values: $0, \pm 2, \pm 4 \ldots$ )

(possible values: $1, \pm 3, \pm 5 \ldots$ )

The proposal in (9) may seem bizarre and unworkable. It should not be interpreted as a claim that morphological representations have access to the concept of a modulus. Rather, it should be taken as a placeholder, an implementational post-it note of sorts that amounts to a statement that generational cyclicity may be a category to which the grammar is sensitive. Indeed, harmony-sensitivity can be observed outside of the pronominal domain, in particular within the switch-reference system of Mparntwe Arrernte (Wilkins 1988).

Urreye kweke artne-lape-ke itne lhe-rlenge /-mele

boy small cry-along-PFV 3PL go-DIFF.SBJ SAME.SBJ

'The little boy cried as they walked along.'

In both variants of (10), there is a group of people walking together, of whom one is a crying boy. When lhe-rlenge is used, all members of the group are generationally harmonic, except for the boy, who is disharmonic. When lhe-mele is used, all members of the group are harmonic. This datum strongly suggests that the grammar needs access to some sort of formal harmonic features, whether or not they resemble anything like (9).

Third, suppose that male EGO is further specified for a moiety feature. Outsiders are underspecified for moiety. Agnate groups are groups in which the moiety features of all members agree. Non-agnate groups are all other groups. (As cognation does not play a role in the grammar, there is no need to propose a $[ \pm \mathrm{C}]$ feature.)

(11) Gender \& moiety features
a. moieties AC, AD: $[+\mathrm{A}]$
b. moieties BC, BD: $[-\mathrm{A}]$
c. agnate: $[\alpha \mathrm{A}, \alpha \mathrm{A}]$
d. non-agnate: $[\alpha \mathrm{A}, \beta \mathrm{A}],[\alpha \mathrm{A}, \emptyset \mathrm{A}]$ 
5. Non-agnate as unmarked. Given the toy implementation in section 4 , it becomes possible to propose the following correspondence rules for the suffixes.

Vocabulary entries

a. $\quad[-$ singular, -augmented $] \leftrightarrow$ rn $/[+$ author; $\alpha \mathrm{A}, \alpha \mathrm{A} ; \mathbb{G} \equiv 0 \quad(\bmod 2)]$

(allomorph of dual in the environment of first person agnate-harmonic)

b. $\quad[-$ singular, -augmented $] \leftrightarrow$ athir

(elsewhere allomorph of dual)

c. $[\alpha \mathrm{A}, \alpha \mathrm{A} ; \mathbb{G} \equiv 1 \quad(\bmod 1)] \leftrightarrow$ ak

(disharmonic marker)

d. $[\alpha \mathrm{A}, \beta \mathrm{A}] \leftrightarrow$ anth

(non-agnate marker)

e. $\quad[-$ singular, +augmented $] \leftrightarrow$ arii $/[-$ author, $\alpha \mathrm{A}, \alpha \mathrm{A} ; \mathbb{G} \equiv 0 \quad(\bmod 2)]$

(allomorph of plural in the environment of non-first person agnate-harmonic)

f. $\quad[-$ singular, +augmented $] \leftrightarrow$ ar $/[+$ author, $\alpha \mathrm{A}, \alpha \mathrm{A} ; \mathbb{G} \equiv 0 \quad(\bmod 2)]$

(allomorph of plural in the environment of first person agnate-harmonic)

g. $\quad[-$ singular, +augmented $] \leftrightarrow$ ir

(elsewhere allomorph of plural)

The task of proposing rules to account for the stem allomorphy proves much more complicated. Consider the ang- $m p i l$ - alternation in the second person dual forms. If this is indeed an $\mathrm{ABB}$ distribution, then one could propose that ang-is the elsewhere form, and mpil- is the allomorph that appears in the agnate-disharmonic (set II) and non-agnate environments (set III).

\section{Hypothesis A: ABB suppletion}

a. [-author, +participant $] \leftrightarrow$ mpil / AGNATE-DISHARMONIC, NON-AGNATE

b. $\quad[$-author, + participant $] \leftrightarrow$ ang

Given the toy features in $(8,9,11)$, however, this seems highly implausible. By definition, the two categories are discordant in terms of the agnation features: agnate-disharmonic forms require all referents to have a matching value of the $[ \pm \mathrm{A}]$ feature, whereas non-agnate forms require the presence of at least one mismatched referent. Furthermore, the non-agnate set is generation-insensitive: it applies equally to groups that are non-agnate and harmonic (e.g., a man and his grandmothers) as well as groups that are non-agnate and disharmonic (e.g., a man and his aunts). There is no way to write a context of insertion that unifies the environments in (13a): the agnate-disharmonic and non-agnate categories are neither in a containing or overlapping relationship. It would become necessary to propose two rules realizing the same form, each with a different context of insertion, or to propose an alternative featural architecture completely.

What if mpil- were proposed as the elsewhere form? After all, it is compatible with agnatedisharmonic, non-agnate-harmonic, and non-agnate-disharmonic groups. It is further compatible with groups of outsiders, for whom generational and moietal specifications are unknown, obscure, or irrelevant. Consequently, ang-would be the allomorph restricted to the highly specific agnate-harmonic environment.

Hypothesis B: $A A B$ suppletion

a. $\quad[$-author, +participant $] \leftrightarrow$ ang $/[\alpha \mathrm{A}, \alpha \mathrm{A} ; \mathbb{G} \equiv 0 \quad(\bmod 2)]$

b. $\quad[$-author, +participant $] \leftrightarrow$ mpil

Crucially, this requires reversing the categorial orders given by Hale and Yallop in their grammatical descriptions. The non-agnate forms should not be listed last in the paradigm as set 
III forms, but rather first as the least marked and distributionally freest forms. Likewise, the agnate-harmonic forms should be listed last, as they are the most marked and most restricted forms.

It bears emphasizing that this study is by no means committed to the psychological reality or theoretical utility of the generational and moietal features proposed in (8-9). They are merely toy features used here to illustrate the difficulty of combining agnate-disharmonic and non-agnate (and generation-insensitive) forms into a natural class with a shared feature that could trigger co-suppletion. In the case of comparative suppletion, the ordering of positive $>$ comparative $>$ superlative is defensible on multiple grounds, not the least semantic tractability and crosslinguistic morphological transparency. In contrast, generation- and moietysensitivity are typologically rare phenomena, providing even rarer opportunities to observe transparent containment or overlap is unattested. Consequently, more work has to be done to justify the categorial ordering onto which *ABA distributions are projected. Impressionistic surface inspection - as well as historical descriptive practices-may lead one to mistakenly conclude that non-agnate forms belong to the 'final', most representationally complex category, even as it seems to be the 'initial', least marked category.

Even more importantly, these data suggest that *ABA patterns can be observed in a markednessdecreasing sequence (agnate-harmonic $>$ agnate-disharmonic $>$ non-agnate). Even if Table 2 is flipped to yield a markedness-increasing sequence, it does not seem possible to analyze the data in terms of containment, if the non-agnate is not properly contained by the agnatedisharmonic (indeed, they are featurally and distributionally antagonistic categories). Although syntacticosemantic analysis of these data shall be left to future work, it does not seem premature to suggest that the task of setting up a paradigm to fish for *ABA domains is not always a simple one, and that *ABA domains are not uniform in terms of their underlying featural or cartographic architecture.

6. Kinship terminology. One wonders if there could be *ABA distributions that are even less amenable to featural decomposition. This section pursues an evanescent consideration of permissible co-lexicalizations within the kinship domain.

Héritier's First Fundamental Law of Kinship (Pye 1997)

Cross-solidarity is never stronger than parallel solidarity and a cross-relation between individuals or groups is never the implicit basis of equivalence or identity.

More concretely, the law forbids the existence of a language in which a single word can be used to refer to both the father and maternal uncle, to the exclusion of the paternal uncle. Contiguous co-lexicalizations, in contrast, are all possible and attested. (Certainly, these facts also hold for female kin, and for cousin terminology as well: a language is not expected to have a term that refers to both siblings and cross-cousins [e.g., children of the maternal uncle], to the exclusion of parallel cousins [e.g., children of the paternal uncle].)

If syncretism is limited to cases of formal identity in which an inflectional or grammatical contrast is neutralized, then it is unclear how to classify the co-lexicalizations in Table 3. In the approach proposed by Nevins (2010), kin terms do decompose featurally. One could plausibly propose a theory of lineality features that generate the data above, thereby reframing Héretier's First Fundamental Law as an (absolute) syncretism-constraining contiguity effect. In contrast, if kin terms do not decompose as a result of their status as content (and not function) 
FATHER PATERNAL UNCLE MATERNAL UNCLE

\begin{tabular}{|c|c|c|c|}
\hline ABC: Turkish & baba & emme & dayi \\
\hline AAB: Seneca & hanih & $\underline{\text { hanih }}$ & hocnoseh \\
\hline ABB: English & $\overline{\text { father }}$ & $\overline{\text { uncle }}$ & uncle \\
\hline AAA: Malay & bapa & bapa & bapa \\
\hline$* \mathrm{ABA}$ & father & uncle & father \\
\hline
\end{tabular}

Table 3. *ABA in parental generation male kin.

words, then *ABA effects unassociated with syntactic hierarchical structure exist. Wierzbicka (2013 et seq.) offer many more arguments against decomposition on the basis of emic implausibility, grounded as kin terms are in deeper facts about social organization and cognition. No attempt will be made here to mediate between these positions, as the conditions of possibility for their advancement alone suffice to shore up the major claim of this study, which is that contiguity domains may be much more heterogeneous in their etiology and distribution than previously imagined.

7. Conclusion. Surface *ABA is observable in many pockets of natural language, and kinship may be more than ordinarily welcoming of these patterns, which are visible at the level of allomorphy, syncretism, and co-lexicalization. The use of surface *ABA as a diagnostic for syntactic hierarchical structure, especially containment structure, should be performed cautiously and judiciously. A given *ABA effect may be correlated to very different types of featural architectures (e.g., markedness-increasing feature cumulation vs. markedness-alternating feature overlapping). For grammatical systems in which markedness relations are more obscure, an apparent *ABA effect may be epiphenomenal to the manner in which the paradigms were set up. Nor can the possibility that at least some *ABA effects result from system-external conditions can be fully dismissed. The documentation and classification of multiple, distinct natural classes of contiguity effects is sure to prove a tantalizing avenue of future work.

\section{References}

Adamson, Luke. 2019. On containment and syncretism in English preterites and participles. Proceedings of the Linguistic Society of America (PLSA) 4. 54:1-15. https://doi.org/10.3765/plsa.v4i1.4555.

Anderson, Stephen R. 1992. A-morphous morphology. Cambridge, UK: Cambridge University Press.

Bobaljik, Jonathan. 2012. Universals in comparative morphology: Suppletion, superlatives, and the structure of words. Cambridge, MA: MIT Press.

Caha, Pavel. 2008. The case hierarchy as functional sequence. In Marc Richards \& Andrej L. Malchukov (eds.), Scales. 247-276. Leipzig: Institut für Linguistik.

Caha, Pavel. 2017. How (not) to derive a *ABA: The case of blansitt's generalisation. Glossa: $A$ Journal of General Linguistics 2(1). 84. http://doi.org/10.5334/gjgl.348.

Hage, Per. 1997. Unthinkable categories and the fundamental laws of kinship. American Ethnologist 24(3). 652-667.

Hale, Kenneth L. 1966. Kinship reflections in syntax: Some Australian languages. Word 22 (1-3). 318-324. 
Harbour, Daniel. 2011. Valence and atomic number. Linguistic Inquiry 42(4). 561-594. https://doi.org/10.1162/LING_a_00061.

Harbour, Daniel. 2016. Impossible persons. Cambridge, MA: MIT Press.

Jabłońska, Patrycja \& Svetoslav Marinov. 2011. Polish nominalization and the containment hypothesis. Presentation at the 5th Workshop on Nominalizations, University of Stuttgart.

McConvell, Patrick, Piers Kelly \& Sebastien Lacrampe (eds.). 2018. Skin, kin and clan: The dynamics of social categories in indigenous Australia. Canberra: Australian National University Press.

Moskal, Beata. 2018. Excluding exclusively the exclusive: Suppletion patterns in clusivity. Glossa: A Journal of General Linguistics 3(1). 130. http://doi.org/10.5334/gjgl.362.

Nevins, Andrew. 2010. The applicability of theories of phonological contrast to kinship systems. Behavioral and Brain Sciences 33(5). 398-399. https://doi.org/10.1017/s0140525x10002402.

Smith, Peter W., Beata Moskal, Ting Xu, Jungmin Kang \& Jonathan Bobaljik. 2018. Case and number suppletion in pronouns. Lingbuzz/003110.

Wierzbicka, Anna. 2013. Kinship and social cognition in Australian languages: Kayardild and Pitjantjatjara. Australian Journal of Linguistics 33(3). 302-321.

Wilkins, David. 1988. Switch reference in Mparntwe Arrernte (Aranda): Form, function, and problems of identity. In Peter Austin (ed.) Complex sentence constructions in Australian languages. 141-176. Amsterdam: John Benjamins.

Yallop, Colin. 1977. Alyawarra, an aboriginal language of central Australia. Canberra: Australian Institute of Aboriginal Studies

Yallop, Colin. 1982. Australian aboriginal languages. London: Andre Deutsch. 